\title{
From incident reporting to the analysis of the patient journey
}

\author{
Patricia Trbovich, ${ }^{1,2}$ Charles Vincent $^{3}$
}

\begin{abstract}
'University of Toronto, Toronto, Ontario, Canada ${ }^{2}$ North York General Hospital, Toronto, Ontario, Canada ${ }^{3}$ Department of Experimental Psychology, University of Oxford, Oxford, United Kingdom
\end{abstract}

\section{Correspondence to}

Dr Patricia Trbovich, University of Toronto, Toronto, ON M5S 3H7 Canada;

patricia.trbovich@utoronto.ca

Accepted 11 September 2018 Published Online First 18 October 2018

\section{SLinked}

- http://dx.doi.org/10.1136/ bmjqs-2017-007457

\section{Check for updates}

(C) Author(s) (or their employer(s)) 2019. No commercial re-use. See rights and permissions. Published by BMJ.

To cite: Trbovich P, Vincent $C$. BMJ Qual Saf

2019:28:169-171.

\section{PATRICIA TRBOVICH AND CHARLES VINCENT}

Incident reporting has been a mainstay of patient safety initiatives throughout the world, but its purpose and potential for stimulating safety improvements are still much debated. Record review studies of adverse events revealed the nature and scale of harm to patients, and it was initially hoped that incident reporting systems would capture these adverse events on an ongoing basis. ${ }^{12}$ This epidemiological dream was never realised; studies showed that incident reporting was actually very poor at identifying adverse events. ${ }^{3}$ Furthermore, incident reporting, record review and other systems such as pharmacy reports capture very different types of problems, which means that combining information sources can provide a more complete picture of safety issues. ${ }^{45}$

In this issue, de Vos and colleagues ${ }^{6}$ extend this argument to suggest that we should draw on a number of data sources and examine the linkages between them at the patient level. Their study in Dutch hospitals examined the links between patient complaints, incident reports and adverse events. Holland has a reporting system for adverse events that is embedded in the medical record and used routinely by physicians. Incident reporting, in contrast, has evolved primarily to capture process problems (though patient accidents are still included). These arrangements differ from the UK, for instance, where incident reporting systems are still the primary means of reporting adverse events. The Dutch system allows for a much clearer separation between these data sources, which is advantageous for the study, but which limits the potential extension of its methodology to countries which do not have a means of routinely recording adverse events.

De Vos et $a l^{6}$ examine a number of different relationships between incidents, adverse events and complaints. In over 26 383 admissions, 1599 (6.1\%) of incidents were reported and 4838 (18.3\%) adverse events were recorded. Only 33 complaints were made, and only 10 of those were linked to incidents or adverse events, a salutary corrective to anyone arguing that societies are increasingly litigious and liable to complain. Patients seem if anything overtolerant of problems in their care. The adverse event rate appears high, but adverse events are conceived very broadly seemingly including any inflammation or infection and such issues as 'symptoms without diagnosis'. The willingness of Dutch physicians to openly and routinely record problems in patient care and harm to patients is impressive.

\section{LEARNING FROM A SERIES OF EVENTS}

De Vos and colleagues ${ }^{6}$ find that incidents (process problems) may precede or follow adverse events with roughly equal frequency. In their review of selected clinical themes, different patterns emerge depending on the clinical issue considered. Delirium was, not surprisingly, associated with patient falls and other accidents. In contrast, only two of 97 recorded incidents of failure to provide venous thromboembolism (VTE prophylaxis led to, or were associated with, a subsequent embolism. These associations are interesting, and the exploration valuable, but the emerging patterns can only ever be tentative associations because of the unsystematic nature of incident reporting.

Analyses of this kind highlight the tension between treating incidents reports as epidemiological rather than simply as triggers for events requiring further review. De Vos et $a l^{6}$ are exploring the limits of these systems' ability to provide epidemiological data of sufficient rigour to discern relationships and thus inform learning. However, incident reporting 
systems, even when as sophisticated as described by de Vos et $a l,{ }^{6}$ are always somewhat random selections of phenomena from the patient journey and will never attain the status of epidemiological data. ${ }^{2}$ It is hard to escape the conclusion that, if one wanted to explore the links between, for instance, delirium and falls, it might be better to focus on the relevant data in the first place. The strength of incident reporting is that it can capture idiosyncratic reports of unusual events with potential for new learning rather than provide a reliable count of routine familiar problems. ${ }^{7}$

Even if we conclude that these systems are not adequate for investigating causal relationships, there could still be value in linking data. We might identify previously unsuspected patterns and relationships that could then be further investigated in more formal studies. However, we might also argue that there is particular value, as de Vos and colleagues ${ }^{6}$ imply, in examining cases in which a series of adverse events and incidents occur. Adverse event cascades ( $>3$ adverse events) were suffered by 845 unfortunate people from 26823 admissions.

Why might it be more advantageous to examine cascades than single events? These cascades are probably more harmful to patients than single adverse events but, while that increases motivation to learn, it does not in itself mean that cascades will be more revealing. The greater value perhaps lies in the longer timescale of such analyses and the ability to examine actions taken, or not taken, in the aftermath of adverse events that potentially influence the patient's later course. Typically, analyses of incidents or adverse events focus on the causes and contributory factors preceding the event. In cascades, we see the causes and the response to deterioration and crisis and a potentially much longer unfolding story. This suggests that our analyses of safety and quality, while often triggered by specific events, should begin to examine much longer time periods to more truly reflect the patient journey and the wider healthcare system.

\section{HOW CAN WE REFLECT THE HEALTHCARE SYSTEM IN OUR ANALYSES?}

Most analyses of adverse events examine relatively short time periods and usually focus on a single setting such as a hospital. However, a patient receives care in many settings and the various interactions that occur along the patient journey that create the conditions for an incident may involve multiple individuals, technologies, institutions and organisations. These wider sociotechnical interdependencies may be revealed but are seldom addressed in typical local investigations. ${ }^{8}$

Hospitals, for example, sometimes identify problems, such as the design of equipment, that could never be resolved locally. ${ }^{9}$ Achieving a full understanding of such issues requires an appropriate level of resources and expertise for the comprehensive assessment of aggregate incident reports and the development and implementation of objective, scientifically-based, corrective actions. ${ }^{10}$ Resolving such problems requires a still wider collaboration with patients, families, primary care clinicians, manufacturers and regulators. ${ }^{11}$

Teams could potentially be formed to comprehensively assess and inform corrective actions to address deeper system problems, but this rarely happens in healthcare. In contrast, the Federal Aviation Administration (FAA) and the Nuclear Regulatory Commission (NRC) have oversight and dedicated resources for incident investigations across systems. When a system problem is identified, the FAA and NRC can apply the analytic resources of a core agency with multiple relevant experts; they do not expect that these wider problems will be solved by the actions of individual airlines or power plants. Furthermore, they can require corrective actions and improvements from any part of the system, including organisations providing services, regulators and governments.

Healthcare has few examples of a structured, system-wide approach to investigations despite having similar risk and liability of serious adverse events. In a recent development, the UK National Health Services recently launched the Healthcare Safety Investigation Branch initiative, dedicated to investigating and learning across the entire healthcare system. ${ }^{12}$ This initiative is a prime example of the type of specialist agency, necessary to improve healthcare work systems and generate novel insights for patient safety that the public and patients deserve.

\section{TOWARDS THE ANALYSIS OF THE PATIENT JOURNEY}

The analysis of the patient journey, rather than particular events, is particularly critical if we wish to go beyond the confines of the hospital and examine healthcare in the context of people's lives. ${ }^{13}$ Healthcare is increasingly being delivered in the home and patients and families are, for the majority of their lives, managing their own care. We ideally will need to capture a year in the life of a patient and their healthcare if we are to fully understand the successes, hazards and deficiencies across the whole healthcare system. As demonstrated by de Vos et al, ${ }^{6}$ individual data sources can provide different perspectives on the same topic if they are linked. A central repository for searching sources from multiple existing systems or encouraging shared learning between organisations operating these different systems may hold the key to reflecting the patient journey. Our primary informants will of course be the patient and family. Only they can tell us about care in the home and about the critical issues of communication and coordination of care, which are largely invisible to healthcare professionals.

In the future therefore our safety and quality analyses will need to include care in the home and to extend over much longer time periods. The linkage of 
data sets from different contexts, and the relationships between events explored by de Vos and colleagues, ${ }^{6}$ will be critical to build a picture of the full patient journey across the wider system and mirror the actual experience of the patients and their families.

Funding The authors have not declared a specific grant for this research from any funding agency in the public, commercial or not-for-profit sectors.

Competing interests None declared.

Patient consent Not required.

Provenance and peer review Commissioned; internally peer reviewed.

\section{REFERENCES}

1 Department of Health Expert Group (Chairman, CMO). An organisation with a memory: report of an expert group on learning from adverse events in the NHS chaired by the Chief Medical Officer. London, England: Department of Health, 2000.

2 Vincent C. Incident reporting and patient safety. BMJ 2007;334:51.

3 Sari AB, Sheldon TA, Cracknell A, et al. Sensitivity of routine system for reporting patient safety incidents in an NHS hospital: retrospective patient case note review. BMJ 2007;334:79.

4 Weingart SN, Toro J, Spencer J, et al. Medication errors involving oral chemotherapy. Cancer 2010;116:NA-64.
5 Olsen S, Neale G, Schwab K, et al. Hospital staff should use more than one method to detect adverse events and potential adverse events: incident reporting, pharmacist surveillance and local real-time record review may all have a place. Qual Saf Health Care 2007;16:40-4.

6 de Vos MS, Hamming JF, Chua-Hendriks JJC, et al. Connecting perspectives on quality and safety: patient-level linkage of incident, adverse event and complaint data. BMJ Qual Saf 2019;28:180-9.

7 Macrae C. The problem with incident reporting. BMJ Qual Saf 2016;25:71-5.

8 Dixon-Woods M, Pronovost PJ. Patient safety and the problem of many hands. BMJ Qual Saf 2016;25:485-8.

9 Donaldson LJ, Panesar SS, Darzi A. Patient-safety-related hospital deaths in England: thematic analysis of incidents reported to a national database, 2010-2012. PLoS Med 2014;11:e1001667.

10 Rosenthal J, Riley T, Booth M. State reporting of medical errors and adverse events: results of a 50-state survey. Portland, ME: National Academy for State Health Policy, 2000.

11 Pham JC, Gianci S, Battles J, et al. Establishing a global learning community for incident-reporting systems. Qual Saf Health Care 2010;19:446-51.

12 Macrae C, Vincent C. A new national safety investigator for healthcare: the road ahead. J R Soc Med 2017;110:90-2.

13 Vincent C, Amalberti R, healthcare S. Strategies for the real world. London, England: Springer Open, 2016. 